\title{
Improvement and development in anatomical hepatectomy for hepatocellular carcinoma
}

\author{
Takeshi Takamoto \\ Department of Hepatobiliary and Pancreatic Surgery, National Cancer Center Hospital, Tokyo, Japan \\ Correspondence to: Takeshi Takamoto, MD, PhD. Department of Hepatobiliary and Pancreatic Surgery, National Cancer Center Hospital, 5-1-1 \\ Tsukiji, Chuo-ku, Tokyo 104-0045, Japan. Email: ttakamot@ncc.go.jp. \\ Comment on: Ariizumi SI, Katagiri S, Kotera Y, et al. Improved Mortality, Morbidity and Long-term Outcome after Anatomical Hepatectomy with \\ the Glissonean Pedicle Approach in Patients with Hepatocellular Carcinoma: 30 years' Experience at a Single Institute. Ann Surg 2020. [Epub ahead \\ of print]. doi: 10.1097/SLA.0000000000004311.
}

Submitted Jun 19, 2021. Accepted for publication Jun 30, 2021.

doi: 10.21037/hbsn-21-247

View this article at: https://dx.doi.org/10.21037/hbsn-21-247

Liver resection is one of the best practical curative options for hepatocellular carcinoma (HCC). Since HCC spreads via portal venous system $(1,2)$ and develops intrahepatic metastases, resecting tumor-bearing territory, so-called anatomical resection, is proven to provide higher curability than non-anatomical limited liver resection (3). Generally, HCC arises from a damaged liver and hepatectomy is always accompanied by the risk of massive bleeding due to liver mobilization and transection with a background of the blood coagulation disorder and insufficiency of volume and function of the remnant liver resulting in postoperative liver failure. Therefore, hepatectomy for HCC should be performed with less blood loss and with necessary and sufficient liver volume remained. To accomplish these two missions, several technical approaches for anatomical hepatectomy were proposed in the 1980s (4). Five decades have passed from the dawning era when the mortality of hepatectomy was reported as high as $20 \%$ (5). Anatomical hepatectomy now becomes a widely performed procedure with reasonable safety (6). But what brings the improvement and development in hepatectomy? Were some inventive surgical procedures excellent? Did the successors of the style work well?

Dr. Ariizumi and his colleagues published "Improved Mortality, Morbidity and Long-term Outcome after Anatomical Hepatectomy with the Glissonean Pedicle Approach in Patients with Hepatocellular Carcinoma" in the Annals of Surgery, 2020 (7). The authors reviewed their 30-year history from 1985, investigating 1953 anatomical hepatectomies by
Glissonean pedicle approach for HCC in Tokyo Women's Medical University, one of the highest volume centers of hepatectomy in Japan. They highlighted the association between continuous reduction of mortality and morbidity ratio and decrement in intraoperative blood loss over 2 milliliters and bile leakage during the period. Another important finding in this article was the association between more prolonged overall survival and fewer major complications. Since it is a retrospective study, it is undeniable that patients with higher life capacity tend to have less morbidity. However, surgeons' careful attempt to prevent postoperative complications, as well as performing precise and oncologically ideal surgery, might improve the effectiveness and curability of surgical treatment for HCC.

According to their analysis, major complications related to mortality were well-known two nightmare scenarios. One is postoperative liver failure after massive bleeding and blood transfusion, and the other is surgical site infection following bile leakage, causing sepsis, then ending with liver failure. Aiming at avoiding these lifethreatening complications, liver surgeons have launched several effective schemes. First, to reduce the occurrence of postoperative liver failure due to insufficiently small remnant liver volume, several criteria in selecting adequate operative procedures were created in the late 1980s $(1,8)$. These criteria indicate the minimum required liver volume after hepatectomy individually, which is defined based on the result of the indocyanine green (ICG) retention test for each patient. The evaluation of liver functional reserve 
by blood load testing methods, in addition to the results of static blood test and Child-Pugh score, undoubtfully contributes to realizing low mortality of hepatectomy (6). Preoperative portal vein embolization is also an invention to avoid liver failure after major hepatectomy (9). These criteria establishment is supposed to be the primary reason for the initial drop of mortality from $6 \%$ to $4.3 \%$ in the 1990s shown in Figure 1 in Dr. Ariizumi's paper. Second, detailed planning for hepatectomy and energy devices utilization reduce intrahepatic blood loss during liver transection. The developments in surgical imaging technology, such as intraoperative ultrasonography, computed tomography, and virtual hepatectomy using 3D simulation software (10), assist liver surgeons in recognizing the adequate liver transection plane, showing the location of liver tumors and major intrahepatic vasculatures hidden in the liver parenchyma. Several contrivances to control liver blood flow, such as intermittent Pringle maneuver, anesthesiological hepatic venous pressure control (11), and IVC manipulation, are also adopted to clarify and dry liver transection plane. The energy devices, including ultrasonic dissectors and bipolar vessel sealing system, can realize less blood loss and less transection time in hepatectomy than the Kelly clamp crush method with numerous surgical thread ligations (12). The invention of energy devices might reduce bile leakage and infectious complications on the cut liver surface. The traditional method of liver transection always requires numerous ligations using surgical silk threads, which can easily become a core of infection. Unnecessary drainage tube placement has been recently avoided (13), which might be associated with avoiding retrograde intraabdominal infection. This shift to energy devices may affect the better overall survival curve in the newest era of 2010-2014. However, we should pay attention to the change of etiology in HCC patients in our country. Thanks to the prevailed strategy of regular screening examination for patients who have a high risk of developing HCC, more and more HCCs were found in the early stage and the background liver is well maintained by controlling viral hepatitis with drugs. In accord with this, the median ICGR15 value and liver cirrhosis percentage shown in this article decrease significantly with the eras. And the availability of several alternative curative treatments for patients who are regarded as high-risk groups for hepatectomy might indirectly improve the outcome of hepatectomy. The local ablation therapy (radiofrequency ablation and microwave coagulation therapy) is a feasible and practical choice, especially for patients who had co- morbidities and general anesthesia is hesitated or deeply located small HCC. The living donor liver transplantation is a possible choice as long as an adequate donor is secured. Therefore, unintentional patient selection for safer and easier hepatectomy might affect the outcome after hepatectomy. Anyway, we should remember that these reductions of mortality and mortality are derived from not only the surgeons' ingenious attempts and efforts but also physicians' and radiologists' contributions.

As the authors showed in the table S2 (7), bile leakage was still observed in $7.3 \%$ in $2010-2014$, although it was a one-fourth ratio of those in 1985-1989. The reason for bile leakage in anatomical hepatectomy always becomes a debate, because peripheral intrahepatic bile ducts would never appear on the liver transection plane theoretically. Would the injury in detaching the Glissonean pedicle in the hepatic hilum be the cause? We would appreciate further analysis on the knack and pitfall in this inherited approach focusing on bile leakage. Because recently, the Glissonean approach is revisited by laparoscopic liver surgeons. They modify and develop this approach to improve the quality of laparoscopic anatomical hepatectomy. The novel equipment, such as laparoscopic magnified view, small surgical stapling devices, and ICG fluoroscopy, brings new perspectives of anatomical hepatectomy.

If I give an answer to the question of why the outcome after anatomical hepatectomy has improved, it would be not only the creative excellence of the surgical technique but the whole package of their treatments based on the Glissonean approach hepatectomy. As Dr. Ariizumi performed in this article, surgeons should regularly re-evaluate our inherited surgical approach to assess whether it is suitable for present patients and to find where to modify using novel technology. The etiology of patients constantly changes, and technology in the medical field keeps improving.

\section{Acknowledgments}

Funding: None.

\section{Footnote}

Provenance and Peer Review: This article was commissioned by the editorial office of Hepatobiliary Surgery and Nutrition. The article did not undergo external peer review.

Conflicts of Interest: The author has completed the ICMJE uniform disclosure form (available at https://hbsn. 
amegroups.com/article/view/10.21037/hbsn-21-247/coif). The author has no conflicts of interest to declare.

Ethical Statement: The author is accountable for all aspects of the work in ensuring that questions related to the accuracy or integrity of any part of the work are appropriately investigated and resolved.

Open Access Statement: This is an Open Access article distributed in accordance with the Creative Commons Attribution-NonCommercial-NoDerivs 4.0 International License (CC BY-NC-ND 4.0), which permits the noncommercial replication and distribution of the article with the strict proviso that no changes or edits are made and the original work is properly cited (including links to both the formal publication through the relevant DOI and the license). See: https://creativecommons.org/licenses/by-nc-nd/4.0/.

\section{References}

1. Makuuchi M, Kosuge T, Takayama T, et al. Surgery for small liver cancers. Semin Surg Oncol 1993;9:298-304.

2. Arii S, Yamaoka Y, Futagawa S, et al. Results of surgical and nonsurgical treatment for small-sized hepatocellular carcinomas: a retrospective and nationwide survey in Japan. The Liver Cancer Study Group of Japan. Hepatology 2000;32:1224-9.

3. Hasegawa K, Kokudo N, Imamura H, et al. Prognostic impact of anatomic resection for hepatocellular carcinoma. Ann Surg 2005;242:252-9.

4. Makuuchi M, Bandai Y, Ito T, et al. Ultrasonically guided percutaneous transhepatic bile drainage: a singlestep procedure without cholangiography. Radiology 1980;136:165-9.

5. Nagao T, Inoue $S$, Goto $S$, et al. Hepatic resection for hepatocellular carcinoma. Clinical features and long-term

Cite this article as: Takamoto $\mathrm{T}$. Improvement and development in anatomical hepatectomy for hepatocellular carcinoma. HepatoBiliary Surg Nutr 2021;10(4):545-547. doi: 10.21037/hbsn-21-247 prognosis. Ann Surg 1987;205:33-40.

6. Imamura H, Seyama Y, Kokudo N, et al. One thousand fifty-six hepatectomies without mortality in 8 years. Arch Surg 2003;138:1198-206; discussion 206.

7. Ariizumi SI, Katagiri S, Kotera Y, et al. Improved Mortality, Morbidity and Long-term Outcome after Anatomical Hepatectomy with the Glissonean Pedicle Approach in Patients with Hepatocellular Carcinoma: 30 years' Experience at a Single Institute. Ann Surg 2020. [Epub ahead of print]. doi: 10.1097/ SLA.0000000000004311.

8. Yokoyama Y, Nishio H, Ebata T, et al. Value of indocyanine green clearance of the future liver remnant in predicting outcome after resection for biliary cancer. Br J Surg 2010;97:1260-8.

9. Makuuchi M, Thai BL, Takayasu K, et al. Preoperative portal embolization to increase safety of major hepatectomy for hilar bile duct carcinoma: a preliminary report. Surgery 1990;107:521-7.

10. Takamoto T, Hashimoto T, Ogata S, et al. Planning of anatomical liver segmentectomy and subsegmentectomy with 3-dimensional simulation software. Am J Surg 2013;206:530-8.

11. Hashimoto T, Kokudo N, Orii R, et al. Intraoperative blood salvage during liver resection: a randomized controlled trial. Ann Surg 2007;245:686-91.

12. Ichida A, Hasegawa K, Takayama T, et al Randomized clinical trial comparing two vessel-sealing devices with crush clamping during liver transection. Br J Surg 2016;103:1795-803.

13. Arita J, Sakamaki K, Saiura A, et al. Drain Placement After Uncomplicated Hepatic Resection Increases Severe Postoperative Complication Rate: A Japanese Multiinstitutional Randomized Controlled Trial (ND-trial). Ann Surg 2021;273:224-31. 